\title{
DEVELOPMENT OF A MOTORCYCLE TRAILER HITCH FOR COMMERCIAL PURPOSES
}

\author{
Riliwan A.Adebayo $^{1}$, Olorunshogo B. Ogundipe ${ }^{2}$, Oladeji G. Bolarinwa ${ }^{1}$ \\ ${ }^{1}$ Department of Research and Development, National Engineering Development Institute (NEDDI), National Agency \\ for Science and Engineering Infrastructure (NASENI), Anambra State, Nigeria. \\ ${ }^{2}$ Department of Mechanical Engineering Landmark University, Omu-Aran, Kwara State, Nigeria
}

\begin{abstract}
The motorcycle trailer hitch is a device used to secure a motorcycle trailer unto a motorcycle for the purpose of towing. The hitch serves as the medium of bringing both the motorcycle and the trailer together to function as a single unit in motion. This paper has described the features and importance of the motorcycle trailer hitch. Furthermore, a locally made motorcycle trailer hitch has been developed, tested and analyzed to show its commercial purposes.
\end{abstract}

Keywords- Trailer hitch, Motorcycle, Commercial, Locally Sourced Materials, Design.

\section{INTRODUCTION}

In many parts of the rural areas and some urban parts of the country especially in the northern part, the use of the vendor trailer or utility trailer for transporting goods and materials from one place to another is drastically becoming louder. But pulling this trailer has always been done manually with the hand, making it a very difficult and time-consuming exercise especially when fully loaded. This makes the beauty and importance of the trailer obscured to many intending users. One of the challenges faced by those who uses the trailer especially for business purposes like clothe, shoe, foodstuff, and water vendors is that the pulling effort required per full trailer load is usually very greater than what is expected of a single man [1]. The vendors tend to get tired in no time and also find it difficult to meet up with time as they could not move over a long distance at a stretch. But since there is a need for the vendors to survive and maximize profit on every of their daily sale, they tend to take the risk of pulling the loaded trailer to their various destinations with their hand but the fact remains that they find it very difficult to ascend hilly roads, pull over some few kilometers before getting tired, takes longer time and effort to pull for long, they cannot reach out to areas that are far from where they are, thereby, limiting the availability of the products transported in the trailer to only the nearby areas and leaving those far areas in scarcity of the same [2]. They also find it difficult to pull the truck over a rough terrain and many of them get fed up in such situation as when they get stuck in sandy, muddy and water-logged areas and they get to ask for the assistance of passers-by to get out of the ditches most times. Many also decide not to carry up to the full trailer capacity due to the effort required. But this will only lead to taking more trips than normal and thereby reducing the efficiency of the process which in turn frustrate the vendor. All these challenges make the trailer to be considered as in-efficient, local and un-applicable industrially [3].

The motorcycle trailer hitch is a device used to secure a motorcycle trailer unto a motorcycle for the purpose of towing [4]. The trailer being an un-powered vehicle requires a powered vehicle to pull it around. The hitch serves as the medium of bringing both the motorcycle and the trailer together to function as a single unit in motion [4]. The hitch is made very flexible in such a way that the motorcycle can perform all its normal modes of movements without any adverse effect apart from the higher drive power demanded from the motorcycle, which in turn causes higher fuel consumption. The hitch connects the trailer directly to the motorcycle without any need for modification. Unlike many other standard motorcycle trailer Hitch that have existed, this does not request any further work before the trailer is towed. All that is required is to simply attach it to the motorcycle and the trailer utilizing the mounting plates and the grip plates respectively. After use, it may be disassembled and kept in a proper safe or taken unto another utility trailer for use due to its portability. The hitch assembly is made in parts and not cast as a unit to allow for easy replacement, repair, and service of any of the parts over time [5-9].

William E.F.(1986), according to this invention, a swivel connection adapted to be interposed between a motorcycle, or other small vehicles, and a trailer being towed thereby to isolate any variation of the vertical orientation of the motorcycle from the trailer. The swivel connection comprises a channel member secured to the usual hitch assembly normally provided for the motorcycle, and a box member secured to the channel member for receiving a spindle member therein. The spindle member is rigidly secured to the box member and extends axially outwardly therefore for rotational connection with a sleeve member secured to the usual tongue provided on the trailer. The rotation connection between the 


\section{International Journal of Engineering Applied Sciences and Technology, 2021 Vol. 6, Issue 5, ISSN No. 2455-2143, Pages 17-23 \\ Published Online September 2021 in IJEAST (http://www.ijeast.com)}

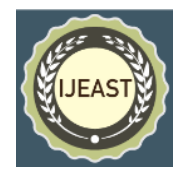

spindle member and sleeve member permits the vertical variations of the motorcycle to be absorbed, thus isolating the trailer therefrom [10-16].

Micheal J.P. (1992) according to him the invention is a hitch device for interconnecting two mobile apparatus, such as a hospital gurney and an IV stand [10]. The hitch device comprises a body having first and second ends, each end having a coupling for attachment to a mobile apparatus, and a monoplanarly flexible intermediate portion disposed between the first and second ends. The intermediate portion includes a chain, which is oriented so that only lateral flexing is permitted when the device is in use. The intermediate portion also includes a resilient tube or spring for biasing the intermediate portion to an axial position. A stop located on the first end prevents upward rotation of the intermediate portion beyond a horizontal position when the device is in use.

Shockley et al., (2011) In this invention a motorcycle hitch assembly is disclosed for attachment to hitch support on a motorcycle for towing a trailer. The hitch assembly comprises a base and a pivotal trailer ball carried by the base for being coupled with the trailer coupling [15]. The trailer ball includes a ball element and a ball shank extending from the ball element having a free end. Pivot support connects the base and the ball shaft so that the trailer ball and base pivot relative to each other generally in a vertical plane so that the trailer ball remains generally vertical as the motorcycle and base lean during turning. A clearance space defined between the free end of the shank and the bottom of the base allows the trailer ball to pivot freely in a vertical plane. The binding between the trailer coupler and the trailer ball element is reduced during turning. According to Andrew B.J.(1997), a towing hitch includes a frame having a forward portion selectively connected to the receiver hitch of a towing vehicle, and a rearward portion having a pair of elongated bars pivotally connected thereto for removable connection to a vehicle to be towed [3]. Each bar has a pivot arm connected to the rearward end thereof, said pivot arm may be folded into a storage position adjacent and parallel to the bars. Selective locking apparatus permits the pivot arms to be extended to a towing position aligned with the bars and locked in the towing position. Terpsma et al (2008) reveals that the trailer hitch assembly includes a receiver portion including a cylindrically shaped cavity, a bushing member received within the cavity of the receiver portion, and a hitch member that includes a shaft pivotally received within the bushing member. At least a selected one of the bushing member and the shaft is constructed of a material that substantially eliminates the need for using a separately applied lubricant during use of the trailer hitch assembly [16]. The hitch member also includes a first jaw member, a second jaw member coupled to the first jaw member and operable between open and closed positions, a primary latch coupled with the second jaw member and operable between a locked position preventing opening of the second jaw member, and an unlocked position allowing opening of the second jaw member, and a secondary latch coupled with the primary latch and operable between a locked position preventing unlocking of the primary hitch may be moved to unlocked position thereof. Amit D. (2004) observes that in many instances, an autonomous vehicle has a trailer attached to it. The trailer readily follows the vehicle's path of motion while it moves forward. However, when the vehicle reverses, for example to correct its path or to get out of a tight corner, the trailer

has a tendency to jack knife [2]. When a vehicle backs up with a trailer attached the trailer never seems to follow the path it is expected to. An un-cooperative trailer while backing can even often confuse drivers with a lot of driving experience. It takes a lot of experience to be able to backup a trailer. For an autonomous vehicle with a trailer, backing with a trailer is a really big challenge as it places additional constraints on the system's path of travel.

This paper focuses on the development of a motorcycle trailer hitch with less complicated components using locally sourced materials for coupling utility trailer unto a motorcycle. II. Experimental results are presented in section III. Concluding remarks are given in section IV.

\section{MATERIAL AND METHODS}

\section{A. Material Selection}

According to Micheal F.A.(2000), the choice of material cannot be made independently of the choice of process by which the material is to be formed, joined, finished, and otherwise treated. Cost enters both in the choice of material and in the way the material is processed. Mild steel was utilized in the development of the hitch due to its availability, machinability and strength to withstand loads. On the other hand, medium carbon steel was used to make the universal joint because of its hardenability property which is not attainable in mild steel [9].

\section{$B$. Design}

The complete CAD design of the motorcycle trailer hitch showing its major component is shown in Fig. 1

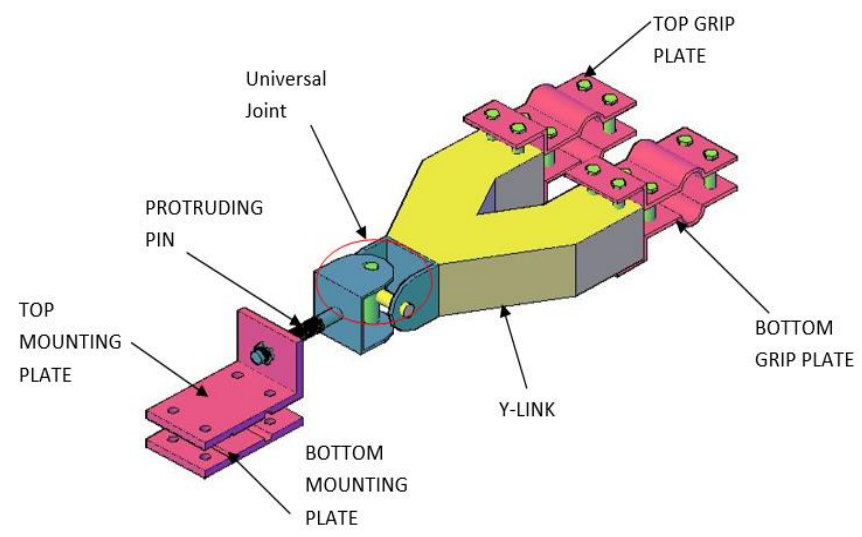


Fig. 1. Motorcycle Trailer Coupling Hitch Components

Fig. 1. DWT Decomposition model

The design of the hitch is carried out by considering the three major elements (Motorcycle, Hitch, and the Trailer) that makes up a motorcycle trailer system, separately and relating them properly and accurately with the interconnecting forces acting at each element-element boundaries by putting into considerations the geometry of each of these elements.

\section{$C$. Motorcycle Design}

Figure 2 shows the free body diagram of the motorcycle disclosing the various forces acting on its various parts and the appropriate dimensions in meters.

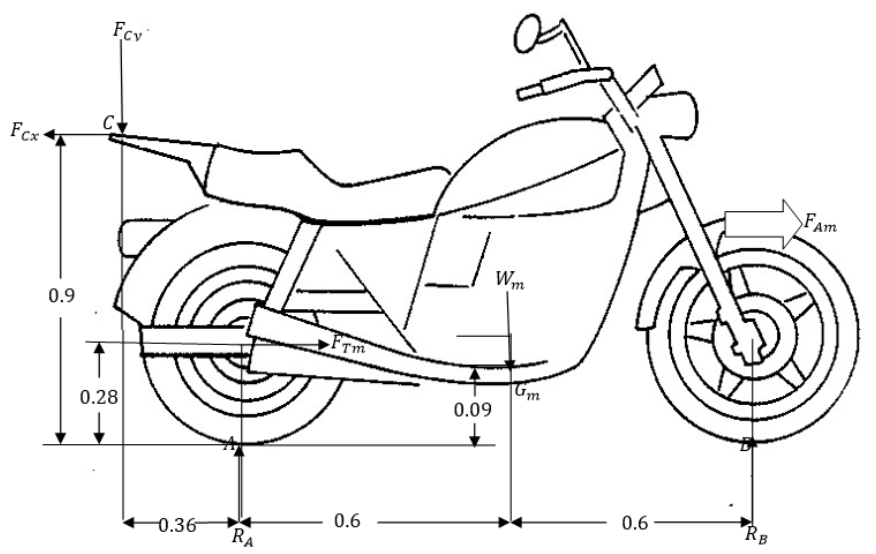

Fig.2. Free Body Diagram of the Motorcycle

Where,

$\mathrm{G}_{\mathrm{m}}=$ center of gravity of the motorcycle

$A=$ centre of the front wheel of the motorcycle

$\mathrm{B}=$ centre of the rear wheel of the motorcycle

$\mathrm{C}=$ centre of the carrier of the motorcycle

$\mathrm{R}_{\mathrm{A}}=$ verticalreactionofthegroundonfrontwheel

$\mathrm{R}_{\mathrm{B}}=$ verticalreactionofthegroundonrearwheel

$\mathrm{W}_{\mathrm{M}}=$ weightofthemotorcycle

$\mathrm{M}_{\mathrm{M}}=$ massofthemotorcycle

$\mathrm{a}=$ linear acceleration of the motorcycle trailer

$\mathrm{g}=$ acceleration due to gravity

$\mathrm{F}_{\mathrm{cx}}=$ horizontal tensile force on the hitch

$\mathrm{F}_{\mathrm{cy}}=$ vertical force on the hitch

$\mathrm{F}_{\mathrm{Am}}=$ accelerative force of the motorcycle

$\mathrm{F}_{\mathrm{Tm}}=$ tractive effort from the motorcycle

$\mathrm{H}_{\mathrm{AB}}=$ height of the centre of the wheels above the ground or radius of the wheels

$\mathrm{H}_{\mathrm{C}}=$ height of the motorcycle above the ground

$\mathrm{H}_{\mathrm{GM}}=$ height of centre of gravity of the motorcycle above the ground

From Fig.1, $\sum F_{y=0} ; R_{A+} R_{B-} W_{M-} F_{c y=0}$

$R_{A+} R_{B-} M_{M \times} g F_{c y}=0$

$R_{A+} R_{B-} 90 \times 9.81-F_{c y}=0$

$R_{A}+R_{B}-882.9-F_{c y}=0$

$\sum F_{x=0 ;} F_{T m-} F_{c x=} F_{A m}$

Therefore, $F_{T m}=\frac{P}{V_{\max }}=\frac{9.3 \times 0.75 \times 3600}{80}=$

$313.875 N(1 H P=0.75 K W)$

Therefore, $313.875-F_{c x=} M_{M \times} a$

$313.875-F_{c x}=90_{\mathrm{x}} a$

$a_{=} \frac{313.875-F_{C X}}{90}$

Taking moment about point $\mathrm{C}$ :

$\sum M_{c=0} ;-F_{T M}\left(H_{C}-H_{G M}\right)-R_{A}(0.36)-R_{B}(1.56)+W_{M}(0.36+0.6)$ $=0$

$-313.875 x 0.62-1.56 R_{B}-0.36 R_{A}+847.584=0$

$-194.6025-1.56 R_{B}-0.36 R_{A}+847.584=0$ $652.9815-1.56 R_{B}-0.36 R_{A}=0$

\section{$D$. Trailer Design}

Figure 3 is a free body diagram of the trailer indicating acting forces and the various dimensions in meters.

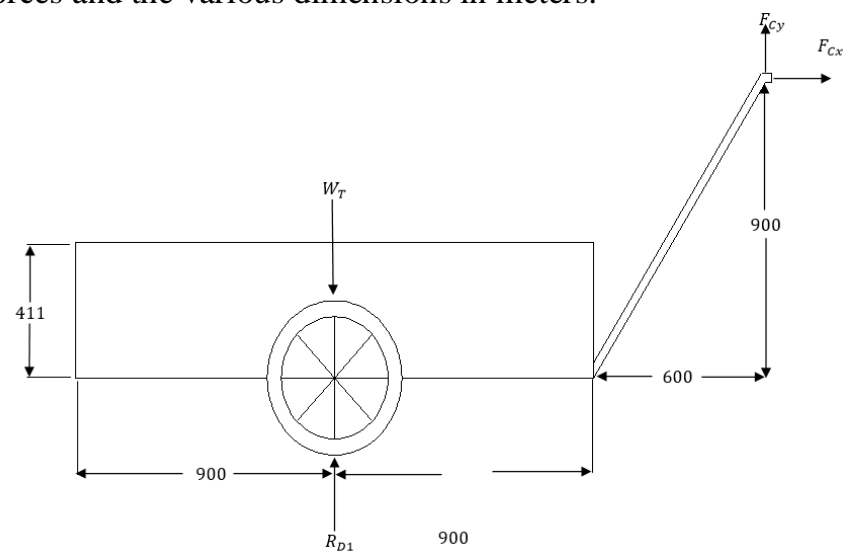

Fig. 3. Free Body Diagram of The Trailer

Where;

$G_{T}=$ centre of gravity of the trailer

$D=$ center ofthetrailerwheel

$R_{D}=$ sum total of the vertical reaction of theground on

$W_{T=}$ weight of the trailer

$M_{T}=$ mass of the trailer

$\sum F_{y=0}, R_{D-} W_{T+} F_{c y=0}$

$R_{D-} M_{M} x g_{+} F_{c y}=0$ 
$R_{D}-400 x 9.81_{+} F_{c y}={ }_{0}$

$R_{D}+F_{c y}=3924$

$\sum F_{x=0 ;} F_{c x=} M_{M} x a$

$F_{c x=400 \mathrm{a}}$

Substituting equation (5) into (2):

Therefore, equation (2) becomes:

$a=\frac{313.875-F_{c x}}{90}=\frac{313.875-400 a}{90}$

$90 x a=313.875-400 a$

$313.875=90 a+400 a$

$313.875=490 a$

$a=\frac{313.875}{490}=0.64 \mathrm{~m} / \mathrm{s}^{2}$

Now, putting $a=0.64 \mathrm{~m} / \mathrm{s}^{2}$ into equation (5):

$F_{c x}=400 \times 0.64=256 \mathrm{~N}$

Taking moment about $\mathrm{C}$ :

$\sum M_{c=0} ; W_{T} x 1.5-R_{D} x_{1.5=0}$

$-M_{M} x g x 1.5+1.5 R_{D}=0$

$-400 \times 9.81 \times 1.5+1.5 R_{D}=0$

$-5886+1.5 R_{D}=0$

$R_{D}=\frac{5886}{1.5}=3924 \mathrm{~N}$

Therefore, $R_{D 1}=1962 \mathrm{Nand} R_{D 2}=1962 \mathrm{~N}$

Substituting $R_{D I}=3924$ Ninto equation (4);

$1962+F_{c y}=3924$

$F_{c y}=3924-1962$

$F_{c y}=1962 \mathrm{~N}$

Putting $\mathrm{F}_{\mathrm{cy}}=1962 \mathrm{~N}$ into equation (1) gives,

$R_{A+} R_{B}-882.9-(1962)_{=0}$

$R_{A+} R_{B}-2844.9=0$

$R_{A+} R_{B}=2844.9$

Solving equations (3) and (6) simultaneously gives:

$R_{A}=3176.72 \mathrm{Nand}_{B}=-331.82 \mathrm{~N}$

\section{E. Hitch Design}

The Hitch consists of three major component parts as follows: a Y-link, Universal joint and a Mounting plate. The hitch coupling is designed and each of the components were analyzed for loads, shear and/or tensile stresses. Figure 4 shows the Y-link of the hitch.

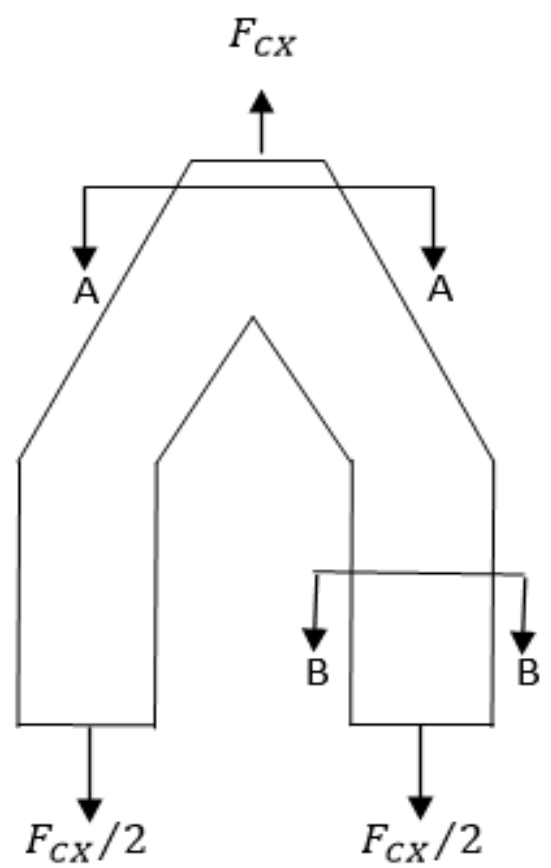

Fig. 4. Y-link

\section{MethodOLOGY}

Considering all design specifications, the Y-link, grip plates, universal joints, mounting plates, and pins were developed, then, these components passed through the buffing and surface finishing process. After the surface finishing, the heat treatment was carried out using an electric furnace. Each of the parts were carefully arranged in the furnace at room temperature and then closed after which it was switched on and the temperature preset to $910^{\circ} \mathrm{C}$ which is the upper critical temperature of the medium carbon steel.A.H. Raymond (1993). Thereafter, the components were painted and assembled.

The assembling of each of the component of the hitch was achieved through the two major joining processes which are permanent (by electric arc welding) and temporary (using bolts fasteners). The systematic steps taken in the assembly of the parts are as follows;

1. Welding the threaded pin to the outer end of the universal joint

2. Welding the other end of the universal joint to the frontal (single) end of the y-link

3. Welding the bottom halves of the grip plates to either sides of the opposite end of the y-link.

4. Lowering the landing gear of the trailer and then positioning the pipe hand between the bottom grip plates carefully. 


\section{International Journal of Engineering Applied Sciences and Technology, 2021 \\ Vol. 6, Issue 5, ISSN No. 2455-2143, Pages 17-23 \\ Published Online September 2021 in IJEAST (http://www.ijeast.com)}

5. Securing the trailer handle in position firmly by covering it with the top grip plate halves and tightening it with bolts and nuts

6. Positioning the mounting plate top half on the motorcycle carriage and properly securing it in position by joining it with the bottom half with bolts and nuts

7. After these the protruding treaded pin from the universal joint is located and gently locked through the hole on the neck of the mounting plate so that it allows for a rotational motion.

Figure 5 shows the the components of the motorcycle trailer hitch. Also, figure 6 shows the heat treatment of the pin.

\section{$G$. Testing}

The test was conducted by loading the trailer appropriately after which the hitch had been properly connected to both the trailer and the motorcycle. The motorcycle was carefully started and driven around while pulling the trailer along. The testing was made over about two kilometres within the school compound by moving through various kinds of roads ranging from smooth to very rough and muddy terrains. (a)

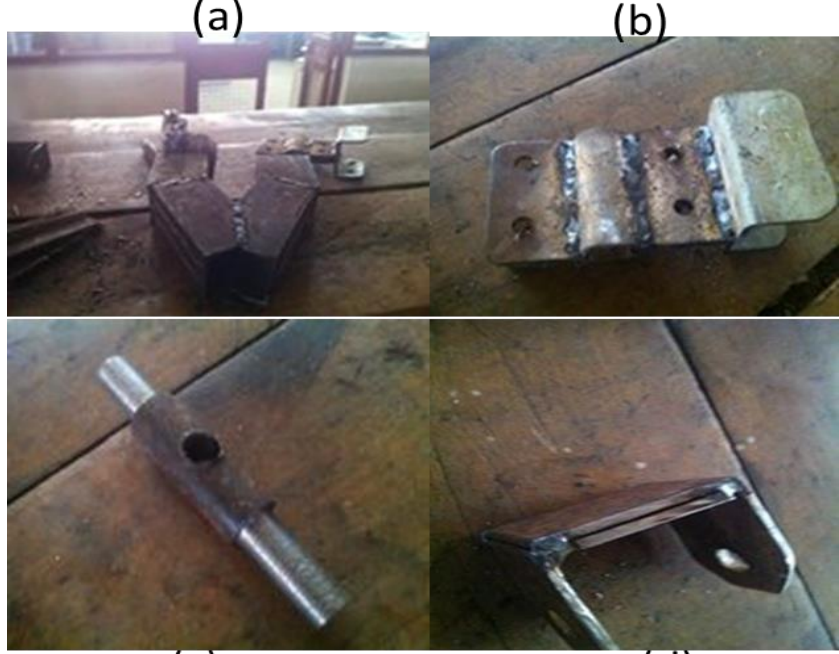

(c) (d)
Fig. 5. (a) Y- link (b) Grip plates (c) Pin (d) U-plate

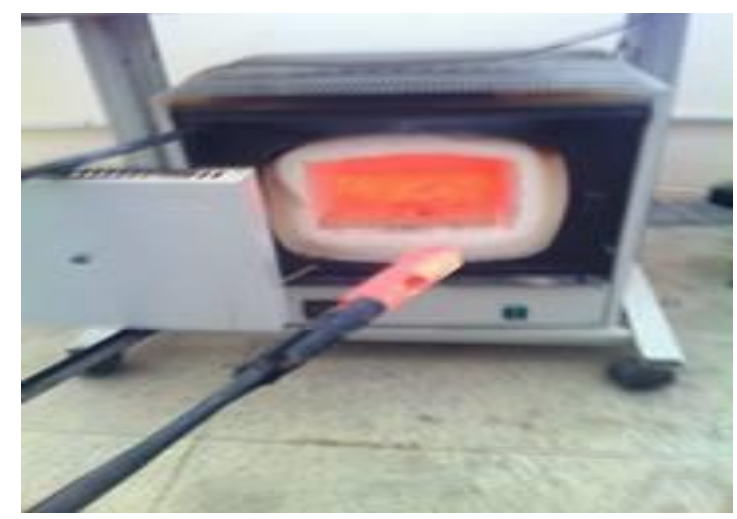

Fig. 6. Heat treatment of the component

Figure 7 shows the attachment of the hitch to the motorcycle and the trailer. There was no cause for any jackknifing, imbalance or swaying of the trailer sideways while on motion due to the ability of the hitch to allow vertical and horizontal deflections and rotations without any dangerous reaction on the trailer itself and the motorcyclist himself. There was no significant problem while negotiating a bend, turning around and most especially when moving over a bump and in rough terrains due to the great ability of the hitch to also allow perfectly for a vertical deflections and rotations at the appropriate point according to the design.

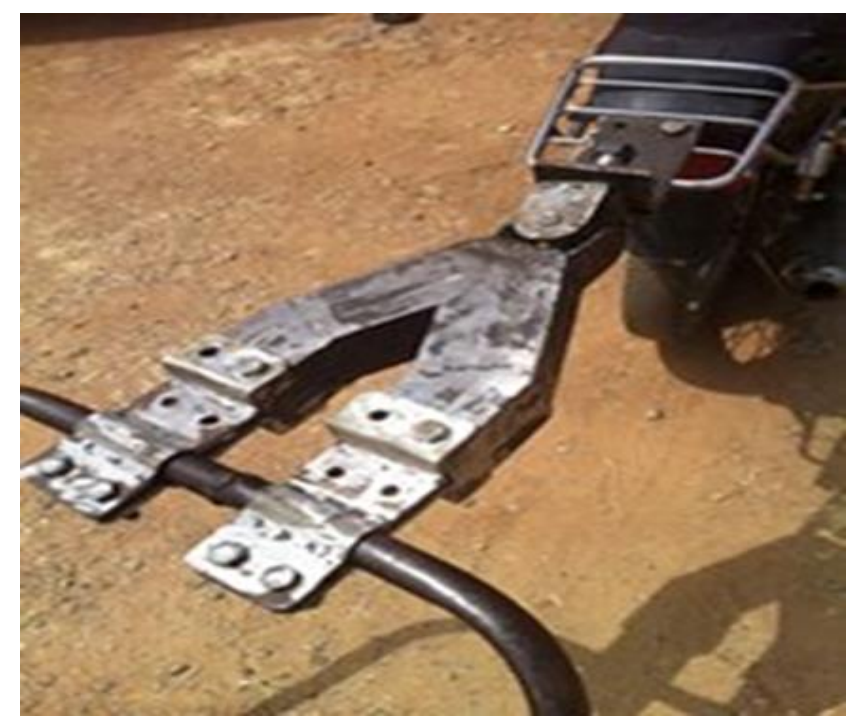

Fig. 7. Hitch Connecting Both Trailer and Motorcycle During Testing

\section{RESULTS AND DISCUSSION}

The result obtained from this work is a motorcycle trailer coupling hitch capable of towing a utility trailer of $400 \mathrm{~kg}$ efficiently. Figure 8 shows the motorcycle trailer hitch in its fully developed state. 


\section{International Journal of Engineering Applied Sciences and Technology, 2021 \\ Vol. 6, Issue 5, ISSN No. 2455-2143, Pages 17-23 \\ Published Online September 2021 in IJEAST (http://www.ijeast.com)}

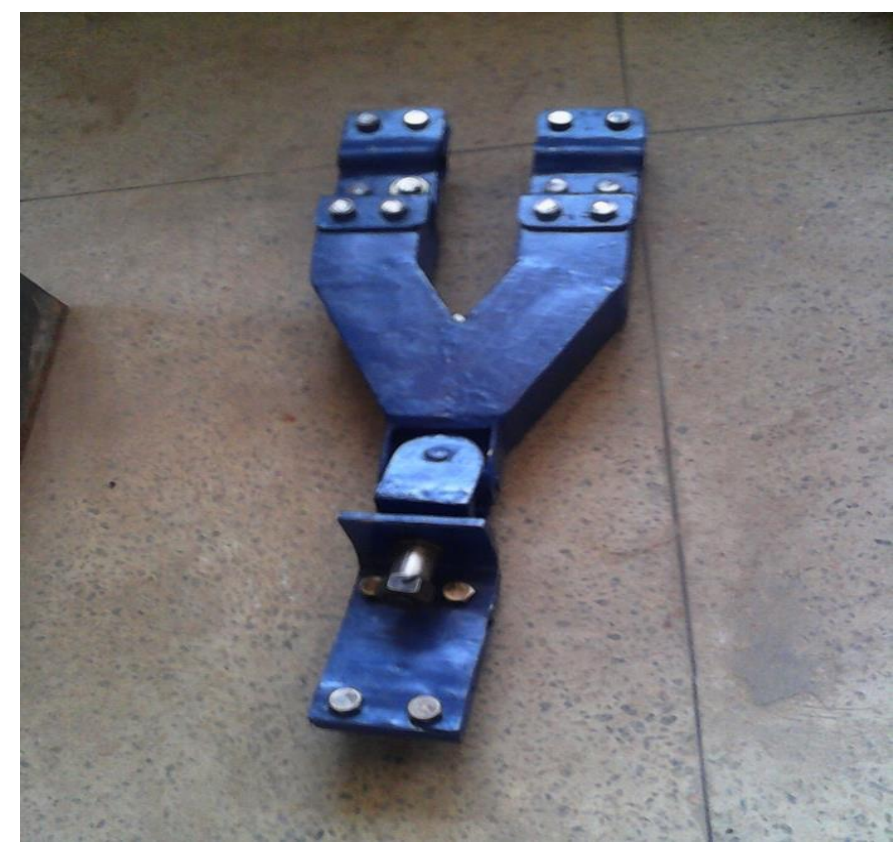

Fig. 8 Fully developed motorcycle trailer hitch

The developed hitch is effective both in cost and in operations. It has a simple shape with less number of components which helps to reduce drastically the possibilities of potential weak point during operation. All the joints in the hitch were either welded or fastened together using Bolts and Nuts. The bolt used is M19 bolts with Nut and Washers. The hitch is rigid enough to withstand the shocks and loading in operation. The universal joint is the only flexible portion of the Hitch at which all the possible motions takes place. The bend on the Top-Mounting plate is filleted in order to reduce stress concentration at that point thereby preventing early failure of the hitch from that member. The mounting plates was made into two halves(top and bottom) to ensure easy repair, service, replacement if need be, and as well to aid ease of de-coupling and transfer for use unto another motorcycle. The grip plates are made into two halves as well for the same reasons. The Ylink member was made with a square-section in order to ensure that the possibility of failure in the hitch is very slim as a square-sectioned member is more safe to use where bending is more pronounced. The coat (blue) gives it a very excellent aesthetic appearance making it very attractive and marketable. The hitch is very portable, presentable, industrially and domestically applicable. Further research will look into stiffness analysis, machine learning approach in hitch analysis, energy usage and its characterization [17-28] to ensure optimal utilization and effective machining processes.

\section{CONCLUSION}

The hitch is less complicated and can be improved upon. Locally sourced, relatively affordable and readily available materials were used such that it can be constructed even at home. Very cheap and affordable and as well straight forward to use, it's a buy-and-fix jig that needs no modification to the existing trailer or motorcycle. The cost of production would be cheaper when produced in masses. The project is majorly designed without any bearing in it and it may even be used for other motorcycle trailers of larger capacities depending on the hitch dimensions and the motorcycle mounting carriage strength. This hitch is a long awaited solution to the menace of unnecessary exhaustion of man power and infringement of the many individuals, organizations or firms desire to haul goods and materials between places at less cost and comfort.

\section{REFERENCE}

[1] William E. (1986) "Swivel Connection For Trailers". Patent-US4765809j

[2] Amit D. (2004) "Enhanced Trailer Backing" M. Eng Thesis, Department Of Mechanical Engineering, University Of Florida, USA.

[3] Andrew B.J. (1993). "Towing Hitch". Patent-Us $5,232,240$

[4] Cart (2013). Available At: Http://Www.Motorcycle/Cart1.Com. Retrieved: 2nd January 2013

[5] Hibbeler R.C. (2001) Mechanics of Materials, Pearson prentice hall.8th Edition, pp. 1- 987.

[6] Jackknifing from Wikipedia (2007), The Free Encyclopedia. Retrieved 13th February 2014.

[7] Jincheng JC125-15a (2011). Available At: Http://Www.Bikez.Com. Retrieved: 19th November 2013.

[8] Khurmi R.S. and Gupta, J.K. (2005) A Text Book Of Machine Design, Eurasia Publishing House(Pvt.) Ltd., New Delhi-110 055, India, pp. 1-1087.

[9] Micheal F.A. (2000) Material Selection In Mechanical Design, Department Of Engineering, Cambridge University England Bulterworth-Heinemann, Linacre House Avenue, Waburn, MA01801-2041. Pp.-20-30.

[10] Micheal J.P (1992) Hitch Device for Interconnecting Mobile Apparatus In Tandem, Patent-Us 4588199a

[11] Motorcycle Trailer History. Available At: Motorcycle Trailer History.Com. Retrieved on 10th July 2013.

[12]Rajput R.K (2010). Strenght of Materials, Multicolor edition. S. Chand, Ram Nagaa, New Delhi. Pp.165 


\section{International Journal of Engineering Applied Sciences and Technology, 2021 \\ Vol. 6, Issue 5, ISSN No. 2455-2143, Pages 17-23 \\ Published Online September 2021 in IJEAST (http://www.ijeast.com)}

[13] Raymond A.H. (1993). Engineering Metallurgy Part 1 Applied Physical Metallurgy, 338 Euston Road, London Nw13bh98 Madison Avenue, New York, Ny10016.6th Edition. Pp.275-297.

[14] C. T. Nnodim, A. M. R. Fath El-Bab, B. W. Ikua, and D. N. Sila, "Estimation of the Modulus of Elasticity of Mango for Fruit Sorting," International Journal of Mechanical and Mechatronics Engineering, vol.19, no. 2, pp. 1-10, 2019.

[15] Shockely et al. (2011) Anti-Binding Motorcycle Trailer Hitch Assembly, Patent-Us 7/988/178 B2

[16] Terpsma et al (2008). Pintle and Receiver Hitch. Patent-Us $7,238,149$

[17] Nnodim, C.T., Fath El-Bab, A.M.R., Ikua, B.W., and Sila, D.N., (2021). Design, Simulation, and Experimental Testing of a Tactile Sensor for Fruit Ripeness Detection". In: Ao SI., Kim HK., Amouzegar M.A. (eds) Transactions on Engineering Technologies, Springer, Singapore, https://doi.org/10.1007/978-981-15-9209-6_5

[18] Nnodim, C.T., Fath El-Bab, A.M.R., Ikua, B.W., and Sila, D.N., (2019). Design and Simulation of a Tactile Sensor for Fruit Ripeness Detection, Lecture Notes in Engineering and Computer Science: Proceedings of The World Congress on Engineering and Computer Science 2019, 22-24 October, 2019, San Francisco, USA, pp. 390395.

[19] Abdulsalam S.O. et al. (2020). Performance Evaluation of ANOVA and RFE Algorithms for Classifying Microarray Dataset Using SVM, In: Themistocleous M., Papadaki M., Kamal M.M. (eds) Information Systems. EMCIS 2020. Lecture Notes in Business Information Processing, vol. 402. Springer, Cham. https://doi.org/10.1007/978-3-03063396-7 32

[20] Nnodim, C. T., Arowolo, M. O., Agboola, B. D., Ogundokun, R. O., Abiodun, M. K., (2021). Future Trends in Mechatronics, International Journal of Robotics and Automation, Vol. 10, No. 1, pp. 24-31, Mar. 2021.

[21] Okhuegbe, S. N., Mwaniki, C., and Akorede, M. F., Optimal Sizing of Hybrid Energy Systems in a Microgrid: A Review (2019). In Proceedings of Sustainable Research and Innovation Conference, pp. 88-100.

[22] Nnodim, C. T., Arowolo, M. O., Ajani, A. A. Okhuegbe, S. N., Agboola, B. D., and Osueke, C. O., (2021). Emerging Advances in the Internet of Things (IoT) Technology for Fast Response to Covid-19 Outbreak With ANOVA-K-NN Implementation, Engineering Letters, vol. 29, no.3, pp.856-863.

[23] Arowolo, M. O., Adebiyi, M. O., Nnodim, C. T., Abdulsalam, S. O., and Adebiyi, A. A., (2021) An Adaptive Genetic Algorithm with Recursive Feature
Elimination Approach for Predicting Malaria Vector Gene Expression Data Classification using Support Vector Machine Kernels", Walailak J Sci \& Tech, vol. 18, no. 17, p. Article 9849 (11 pages).

[24] Onokwai, A. O., Okonkwo, U. C., Osueke, C. O., Olayanju, T. M. A., Ezugwu, C. A., Diarah, R. S., Banjo, S. O., Onokpite, E., Olabamiji, T. S., James J. A., and Nnodim C. T., Ibiwoye, M. (2019). Thermal analysis of solar box cooker in Omu-Aran Metropolis. J. Phys. Conf. Ser. 1378, pp. 1-20.

[25] Chukwulozie, O. P., Chinagorom, N. E., Chukwuneke, C. J. and Nnodim, C. T. (2017). Analysis of Cigarate Production Using Double Exponential Smoothing Model, Academic Journal of Science. 7 (2),pp. 293-308.

[26]Ikubanni, P. P., Adeleke, A. A., Agboola, O. O., Adesina, O. S., Nnodim, C. T., Balogun, A. O., Okonkwo, C. J., \& Olawale, A. O. (2021). Characterization of some commercially available Nigerian coals as carbonaceous material for direct reduced iron production, Material Today Proceedings, https://doi.org/10.1016/j.matpr.2020.12.1167

[27] Olorunshogo B. O., Nnodim, C. T., Oladimeji, S. O., Agboola, B. D., Adeleke, A. A., Ikubanni, P. P., \& Agboola, O. O. (2021). Development and Performance Evaluation of a Manual Briquetting Machine for Biofuel Production, Petroleum and Coal, 63 (2), 509-516.

[28] Sosa, P. B., Makwana, R. D., \& Acharya, G. D. (2018), "Optimization of Machining Parameters on End Milling of EN 8 Back Shaft for Power Press", Trends in Mechanical Engineering \& Technology, Volume 8, Issue 3, pp.49-58, 2018. 